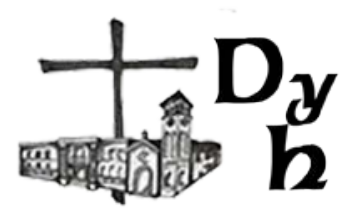

La inmaterialidad como condición del conocimiento

Juan Francisco Pappalardo

Dios y el hombre, vol. 3, n. 1, e038, 2019

ISSN 2618-2858 - https://doi.org/10.24215/26182858e038

https://revistas.unlp.edu.ar/DyH/index

Cátedra libre de pensamiento cristiano - UNLP

Seminario Mayor San José

La Plata, Buenos Aires, Argentina

\title{
LA INMATERIALIDAD COMO CONDICIÓN DEL CONOCIMIENTO
}

\author{
Immateriality as a Condition of Knowledge \\ Juan Francisco Pappalardo \\ jf.pappalardo@gmail.com \\ Seminario Mayor San José - Buenos Aires - Argentina
}

\begin{abstract}
Resumen
El siguiente escrito ha sido fruto del trabajo final correspondiente al Seminario de Síntesis Filosófica, de la carrera de Filosofía, del Seminario San José. El mismo, propone analizar el acto de conocimiento humano destacando la inmaterialidad como aspecto fundante del mismo. El lector encontrará una descripción del acto cognoscitivo humano, proponiendo no solo un análisis del mismo sino su importancia como acto vital, equiparable, si se quiere, al comer y beber. A continuación, se exponen algunos principios antropológicos que sustentan la tesis del conocimiento humano como acto inmaterial. Así mismo, se muestra qué consecuencias se desprenden de tal afirmación, haciendo foco, principalmente, en la locución de la persona. Hacia el final, preguntamos qué pasaría si el acto de conocimiento fuera propio de un ser sin vida inmaterial, considerando a la persona sólo como animal físico, partiendo de la propuesta de Arnold Gehlen, pero extendiendo la respuesta a cualquier tipo de planteo que pretenda entender al ser humano como realidad meramente físico-material.
\end{abstract}

Palabras clave: inmaterialidad, conocimiento, vida, Arnold Gehlen

\begin{abstract}
The following writing has been the result of the final work corresponding to the Seminar of Philosophical Synthesis (San José Seminary). In this paper, author proposes to analyze the act of human knowledge highlighting the immateriality as a founding aspect of it. The reader will find a description of the human cognitive act, proposing not only an analysis of it but its importance as a vital act, comparable, if you will, to eating and drinking. Below, some anthropological principles that support the thesis of human knowledge as an immaterial act are exposed. Likewise, it shows what consequences stem from such affirmation, focusing, mainly, on the person's locution. Towards the end, we asked what would happen if the act of knowledge were characteristic of a being without an immaterial life, considering the person only as a physical animal, based on the proposal of Arnold Gehlen, but extending the answer to any type of proposal that seeks to understand to the human being as merely physical-material reality.
\end{abstract}

Keywords: Immateriality, Knowledge, Life, Arnold Gehlen

Recibido: 04/04/2019 Aceptado: 24/04/2019 Publicado: 16/06/2019 


\section{Introducción}

Si hacemos un breve repaso por las distintas escuelas filosóficas notaremos la diversidad de propuestas gnoseológicas, sobre todo en las corrientes de este último tiempo. De esta manera, evidenciamos un problema clave: la dificultad para explicar el acto de conocer.

Si bien es de lo más tangible corroborar el acto de conocer, no resulta tan evidente la explicación del mismo, es decir, afirmar que conocemos algo es una verdad supuesta de todos los días, pero tratar de echar luz sobre el tema se vuelve engorroso. Lo cual resulta sorprendente, dado que la dificultad de explicar procesos suele provenir de la confusión del mismo, de la oscuridad del asunto, de lo difícil del tema, y en este caso, el acto cognoscitivo es tan claro que carecemos de nociones más claras e inmediatas (Ponferrada, 2010, pág. 93). Frente a esto, proponemos un análisis del hecho cognoscitivo, para luego dar pie al núcleo del trabajo.

Al reflexionar sobre el hecho de conocer, notamos que el acto es nuestro, que actuamos y que lo realizamos nosotros mismos; también, que permanece en nosotros como algo interior, distinto de la acción transitiva (que produce un efecto externo a nosotros); que todo lo que conocemos es algo, es objeto (ob-iectum, enfrente, enfrentado); que, a pesar de estar dentro nuestro, no somos nosotros mismos, sino que podemos notar cierta presencia; por fin, que el acto resulta espontáneo (ex-sponte, desde dentro), lo cual lo transforma en un acto vital. Desarrollaremos a continuación, una explicación más detallada acerca de estas aproximaciones, incorporando terminología y avanzando en torno a nuestra propuesta.

\section{Presupuestos}

Al observar los rasgos esenciales del conocimiento afirmamos la existencia de un sujeto que conoce y aseveramos la existencia de la cosa conocida. Esta realidad, se denomina intelectualidad. 


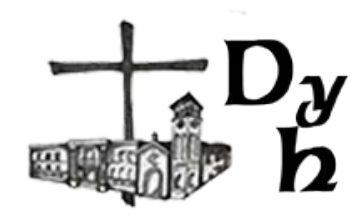

Con el término intelectualidad nos referimos a la inteligencia humana en cuanto que conoce, esto es, la inteligencia, no sólo finita, sino también encarnada, que se hace uno con la forma de las cosas. El intelectualismo tomista no se debe confundir con un mero ejercicio racional despojado de todo contacto con la realidad, un ejercicio ajeno al vivir, ni tampoco debe ser visto como instrumento creador de la misma realidad, dado que adoptar alguna de estas posturas rebajaría y recortaría el alcance vital del acto de conocimiento. El punto de referencia debe ser ubicado en la consideración primaria de la contemplación de lo dado, es decir, la primacía la lleva el develamiento de la realidad. De este modo, el conocimiento humano se nos presenta como operación vital que redunda en la perfección del agente que lo realiza, a la vez que nos abre a la realidad tanto de las cualidades sensibles -conocimiento sensible-, como de las esencias universales -conocimiento intelectual-.

Afirmar esta capacidad de apertura nos permite considerar la recepción de las perfecciones de las cosas que nos rodean y, así, poder decir junto a Sto. Tomás que en el proceso cognoscitivo el alma se hace en cierto sentido, todas las cosas(Tomás de Aquino, Suma Teológica, I,q. 14, a. 1) (a su vez, el Aquinate sigue a Aristóteles, quien acuñó esta expresión).

Conocer es entonces, asimilar en nosotros la forma de algo sin perder nuestra misma forma, asimilar la forma que nos es ajena en cuanto tal, volviéndose lo otro en cuanto otro (Tomás de Aquino, Suma Teológica, I, q. 80, a. 1). En otras palabras, las determinaciones formales que se reciben de las cosas permanecen en su alteridad dado que la presencia de las mismas no es material sino intencional. Esta asimilación vital de las formas de las cosas se realiza sin el concurso de ningún órgano, es decir, se produce de manera inmaterial, determinando, también, el grado de intelectualidad equivalente.

Afirmamos pues, que la inmaterialidad de la forma del cognoscente es la nota de perfección que permite a este hacer partícipe de su acto a otras formas. Es inmaterial puesto que si las cosas se nos hacen cognoscibles en tanto se encuentran separadas de la materia, del mismo modo, aquello en donde sean recibidas estas perfecciones formales deberá ser inmaterial. En consecuencia, las 
perfecciones formales de las cosas, no se hallan en el cognoscente de la misma manera en que se encuentran en la realidad; esto no quiere decir que el cognoscente no aprehenda la realidad, sino que las perfecciones formales existen en la realidad acompañadas de la materia, por la cual quedan determinadas, y se encuentran sostenidas por la misma forma del cognoscente al ser abstraídas, a lo que denominamos ontológicamente: esseintelligibile.

Se establece, de dicha manera, que el acto cognoscitivo se halla en razón directa con la inmaterialidad (Hugón, 1946, pág. 178), que la causa formal del conocimiento y de la cognoscibilidad de la realidad es la inmaterialidad tanto del sujeto como del objeto (Derisi, 1945, pág. 52).

No obstante la nomenclatura clásica, no nos parece del todo correcto utilizar los términos de sujeto y objeto a la hora de referirnos al acto de entender, dado que en este se da cierto tipo de unidad entre el sujeto que conoce y el objeto conocido, al punto que, sujeto inteligente y objeto entendido se hacen uno; además,laconsideracióndelvínculosujeto-objeto,hacereferenciaalapasividaddel conocimiento -sin atender al aspecto activo del cognoscente-, es decir, lo considera como un acto de intuición, llevando al olvido, consecuentemente, que el conocer es ser ${ }^{1}$.

Profundizando en esta última afirmación, decimos que el contenido inteligible de la abstracción -que guarda semejanza con la forma de la cosa real, es decir, que son uno en la cualidad- perfecciona como forma al intelecto, y como consecuencia se produce un unumperfectum. Esta idea la dejábamos ver al principio, al asentar que la inteligencia se hace uno con la forma de las cosas. Como dijimos, el término correcto sería unumperfectum, que alude al intelecto en acto, es decir, al intelecto informado por la speciesintelligibilis ${ }^{2}$. Ahora bien, esta

\footnotetext{
${ }^{1}$ Estas proposiciones encuentran fundamento en la autoridad de EudaldoForment(1946), discípulo del Prof. Francisco Canals, formado en la Escuela Tomista de Barcelona, catedrático de Metafísica en la Universidad de la misma ciudad(Cfr.Forment, 2005, pág. 97).

2 El término species posee un amplio contenido temático y, a la vez, diversos contextos de aplicación; en el texto que componemos será caracterizado como una semejanza de la cosa que es el principio del entender por ser la forma del intelecto y que hace que este se ponga en acto de inteligir(Cfr.Bacigalupe, 2015, pág. 213ss.).
} 


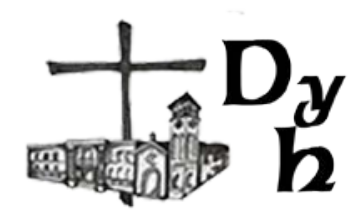

unión no es al modo de la unidad substancial que presentan el alma y el cuerpo (con los cuales el Aquinate establece una analogía), sino que, al ser el conocimiento una operación humana, afirmamos que el intelecto y la species llegan a ser uno en el orden operativo.

Así, la inmaterialidad se presenta como la condición que permite la asimilación de las formas que se encuentran en las cosas por parte del intelecto humano.

\section{Principios Antecedentes}

Aseverar, entonces, que la inteligencia humana conoce de manera inmaterial presupone ciertos principios antropológicos que trataremos a continuación: acerca del espíritu encarnado y del tipo de conocimiento que le es propio.

En primer lugar, la asimilación vital de las formas se encuentra exenta de todo órgano, ya que resulta que una cosa se hace cognoscible en la medida en que se la separa de la materia (Tomás de Aquino, Quaestiones Disputatae de Veritate, q.2, a.2, in corpore), y para que pueda estar en otra cosa, habrá que considerarla prescindiendo de las condiciones de individualidad que la acompañan en su estado natural,y por tanto, convendrá que sea inmaterial también aquello en lo que es recibida la perfección de esa cosa (Tomás de Aquino, Quaestiones Disputatae de Veritate, Ídem). Esto nos coloca en el ámbito inmaterial y, además, en la consideración de la espiritualidad del alma. El alma humana subsiste por sí misma reza la Tesis Tomista $n^{\circ} \mathrm{XV}$ (Hugón, 1946) que nos da la clave para afirmar la inmaterialidad del acto cognoscitivo y comprender lo espiritual de dicho acto.

Que el alma subsista por sí, significa que posee en sí misma razón de ser y existencia. Esto no implica que el alma sea una substancia completa, sino que, más bien, se le atribuye un ser de tipo substancial, sin decir, no obstante, que sea una substancia. Con esto, aclaramos que el alma no depende del cuerpo para su existencia in esse, una independencia ontológica que, por más que se diga de manera negativa, explicita una perfección o una plenitud positiva de ser. Insistimos, nuevamente, que el alma no es una substancia completa a pesar de su perfección, ya que la encontramos unida al cuerpo formando un todo substancial. 
Además de la independencia ontológica, la subsistencia del alma, implica la espiritualidad de la misma. Esto se debe a su incorporeidad, y se ve reforzada la tesis al subrayar la inmaterialidad de los actos de sus facultades: conocer y apetecer -amar, querer-. Las facultades del alma, principios próximos de operación, realizan sus actos propios sin participación del cuerpo, por lo cual asentamos su carácter espiritual; $y$, si afirmamos la espiritualidad de ambas facultades, que son ontológicamente accidentes, por lo cual deben inherir en alguna substancia que sea también espiritual, afirmamos la espiritualidad del alma, ser en el cual existen. Debemos decir, también, que toda facultad sensitiva o apetitiva son facultades del alma, dada la unidad hilemórfica entre el cuerpo y el alma.

Las operaciones próximas del alma que señalábamos en el punto anterior, inhieren en el alma, es decir, provienen del alma humana y se vinculan con ella como los accidentes a la substancia. Centrándonos en el estudio de la inteligencia, definiremos a continuación, el objeto de esta, el sujeto, y por último los actos de conocimiento.

Todo lo que la facultad de intelección alcanza, tanto de manera directa como de manera indirecta, por sí y con sus propios recursos, constituye lo que denominamos objeto adecuado de la inteligencia u objeto común a toda inteligencia. Podría parecernos excesivo ocuparnos de aquel aspecto bajo el cual la inteligencia como tal alcanza su objeto material, dado que sólo tenemos experiencia de nuestro propio pensamiento humano, el cual, es finito y encarnado. Sin embargo es una inteligencia. $Y$ como tal, vislumbra ciertas notas comunes a toda inteligencia. Así, decimos que lo que el entendimiento concibe en primer lugar como el objeto más conocido, y en lo cual resuelve todos sus conceptos es el ente(Tomás de Aquino, Quaestiones Disputatae de Veritate, q. 1, a. 1, in corpore). Con esto, no afirmamos que la única idea que tiene el intelecto humano sea el ente, sino que, la inteligencia alcanza su objeto sub rationeentis, es decir, lo primero que cae en la inteligencia es el ente, y decimos lo primero como aquello que funda y posibilita todo otro conocimiento. El ente aparece como despojado de todas las determinaciones de las cosas puesto que las contiene a todas en su virtualidad. 


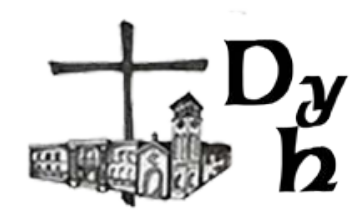

Así, pues, queda aseverado que el objeto común o adecuado de la inteligencia es el ente.

El objeto propio del espíritu humano es el que corresponde a la naturaleza del sujeto cognoscente y que le viene enteramente mediado y proporcionado en el mismo orden de la inmaterialidad. La esencia de las cosas materiales sin las condiciones de la materia 0 , en otros términos, la esencia abstraída de las condiciones singulares y concretas en las cuales hállase envuelto el universal.

El objeto propio de la inteligencia humana es la quidditas de las cosas materiales representada por la imaginación, pero abstracta y universal.

La quidditas está tomada en un sentido más amplio que la esencia metafísica -aquello por lo que una cosa es lo que es-, dado que no llegamos a la esencia de algo directamente, sino más bien, que la captación es progresiva y, de este modo, por quidditas entendemos: quid est res, una naturaleza superficial y parcial, aunque una naturaleza distinta de las cualidades sensibles y del acto de ser, donde además sesubrayasucarácterabstracto.Enotraspalabras, eneltérminoquidditasencontramos tanto la grandeza del pensamiento humano como la miseria o las limitaciones con las que se topa el mismo. Arrojaremos luz sobre este punto a partir de un artículo tomado de la Suma de Teología de Sto. Tomás de Aquino.

Por ser inteligencia, el intelecto humano lleva por objeto el ente, y por ser finita y encarnada, posee ciertas particularidades que determinan este objeto común, debido a que no alcanza el ente directamente más que en una de sus formas, la más baja: el ente material. Y esto se debe, como dice Sto. Tomás, a la condición actual en la que se encuentra nuestro entendimiento: unido a un cuerpo pasible (Tomás de Aquino, Suma Teológica, I, q.84, a.7, in corpore), por lo cual entiende algo recurriendo a las imágenes, es decir, que se vale de los datos de los sentidos y las facultades de la parte sensitiva para entender en acto, a la vez que, también, al querer proponérselo a otro utilizando el conocimiento adquirido, se utilizan imágenes a modo de ejemplares. El fundamento de esto radica en lo que enseña el Aquinate, que la potencia cognoscitiva está proporcionada a lo cognoscible (Tomás de Aquino, Suma Teológica, Ídem), y de este modo, lo que es entendimiento angélico -que no posee vinculación alguna con el cuerpo- conoce lo inteligible, lo que equivale a decir que lleva por objeto propio la substancia 
inteligible separada del cuerpo. En tanto que, el entendimiento humano -unido a un cuerpo como ya señalamos- conoce la esencia en la materia corporal, lo que equivale a decir, que llega por la naturaleza de lo visible a la naturaleza de lo invisible. Lo visible y concreto de los cuerpos es captado por los sentidos, y a ellos recurre el entendimiento, a las imágenes, para descubrir la naturaleza universal.

Así afirmamos que el objeto propio del entendimiento humano es la esencia universal presente en un objeto particular.

\section{Principios Consecuentes}

Desarrollaremos, a continuación, una serie de proposiciones vislumbradas en el apartado anterior, que podrían ser consideradas como principios nucleares del conocimiento, y que además, se desprenden de la doctrina gnoseológica tomista.

En apartados anteriores, aseverábamos que, a causa de la unidad del acto de entender, hablar en términos de sujeto y objeto para designar al entendimiento y a lo conocido, respectivamente, suena inapropiado. Sólo es posible sostener esta terminología en tanto se considere al entendimiento y al inteligible en potencia. De este modo, el entendimiento humano es considerado sujeto en cuanto es intelectual en potencia y necesita ser informado; a su vez, el contenido inteligible, se dice objeto debido a que está en potencia en lo sensible y, para pasar al acto, necesita ser abstraído. Por lo tanto, en acto, tanto el entendimiento y el contenido inteligible, se dicen en estricta unidad.

Esta estricta unidad, que habíamos denominado unumperfectum, se realiza solo cuando la specie informa al intelecto, solo cuando el entendimiento está en acto. Este otro aspecto del entendimiento, la consideración como activo o creativo, pone de manifiesto también que conocer es ser.

«(...) cómo el entendimiento, procediendo de la potencia al acto, no procede sino a la perfección de su ser, y como el entender no es otra cosa que su ser, y la especie, la forma según la cual es aquel ser» Citado en: (Canals Vidal, 1987, pág. 290). 
Con esta cita de Tomás de Vio (In de Anima, II, c.5), Canals Vidal deja asentado lo que veníamos exponiendo: que cuando el alma cognoscente abstrae y es informada por la especie, el acto de conocimiento trae consigo la identificación con el ser de la cosa. Sabemos que entitativamente el entender es una cualidad que posee el sujeto y, así, cuando se produce el acto de entendimiento el cognoscente se vuelve lo que conoce; «el cognoscente es, no sólo él mismo, sino también todo lo que conoce» (Canals Vidal, 1987).

Además, el Gaetano provee otra afirmación esclarecedora del acto cognoscitivo (la cual es también retomada por Canals Vidal) en donde sentencia «sentir y entender, no son sino cierto ser» (Canals Vidal, 1987, pág. 301). No solo es una excelente glosa al De Anima, sino que, al mismo tiempo, se halla en estrecha vinculación con lo dicho por el Estagirita: el alma es en cierto modo todas las cosas(Aristóteles, L. III), retomando y reforzando la unidad entre el entendimiento y la especie.

Es en este sentido que Santo Tomás de Aquino ha sostenido, en diversas partes de su obra, la capacidad del espíritu humano para dirigirse a la totalidad de lo real. Así declara el Aquinate:

Las naturalezas espirituales están por su esencia más emparentadas con la totalidad que las otras naturalezas. Puesto que todo ser espiritual es en cierto sentido todo lo que es, en cuanto que es capaz de comprender la totalidad de lo que es mediante su facultad cognoscitiva. En cambio, los restantes seres sólo poseen una participación parcial en el ser(Tomás de Aquino, Summa contra Gentiles, III, 112).

Sin embargo, el acto de entender no culmina aquí. Puesto que, fruto de este acto es la locución intelectiva, que no es algo distinto de dicho acto, sino que, pertenece intrínsecamente a él. De este modo, el carácter locutivo del entender, denominado también concepto o verbo mental, encuentra fundamento ontológico en el entendimiento en acto.

Así lo explica Santo Tomás: «El verbo mental no surge de nuestro entendimiento sino en cuanto éste existe en acto: pues simultáneamente es 
existente en acto y está ya en él el verbo concebido». La palabra mental no emana «según el brotar de la potencia al acto, sino que es al modo como surge el acto del acto, como el resplandor de la luz» (Tomás de Aquino, Summa contra Gentiles, IV, c. 14).

A partir de estos textos y a continuación, podemos dilucidar varias características de la locución intelectiva y evitar al mismo tiempo varios errores, relacionados, ante todo, con el representacionismo; agregamos que este error brota principalmente de una disociación entre el acto de entendimiento y la locución intelectiva.

En primer lugar, cabe reafirmar que el conocimiento no es ningún proceso, sino un acto, un acto puro, por lo cual, el entendimiento actualizado no puede suscitar ningún producto distinto de sí. Y, de este modo, se asevera que la locución intelectiva se concibe, no como una cosa distinta, sino como plenitud del acto de entender. Esto también lo decíamos al citar al Cardenal de Vío, ya que el entendimiento, al pasar de la potencia al acto, alcanza la perfección de su ser.

Es en este punto donde se podría plantear cierta objección a lo expuesto, sobre todo haciendo notar una aparente contradicción, dado que si el entendimiento es un acto y no un proceso, ¿cómo es que Tomás de Vío afirma que el mismo pasa de la potencia al acto y alcanza su plenitud? ¿qué tipo de proceso se realiza entonces? ¿qué tipo de potencia es el entendimiento? Para dar cauce a las respectivas respuestas y reforzar lo dicho con anterioridad, nos parece correcto citar la autoridad de Aristóteles, quien distingue dos tipos distintos de potencias: por un lado, aquellas que encaminan su fin al uso, a su actividad, y por otro, aquellas que agregan algo a dicho uso, un producto distinto. Nos enfocaremos en las primeras. Estas, al ser su fin la actividad misma, su actualización -el pasaje de la potencia al acto- se lleva a cabo en la obra misma que realiza, es decir, el acto es el fin "porque la obra es un fin y el acto es la obra" (Aristóteles, Metafísica, 1050a.212). A este tipo de potencia pertenece la intelectiva y, por lo tanto, queda excluida la productividad en ella, puesto que su fin se encuentra en el acto, lo último que alcanza es su actualización; dentro de este esquema, la locución intelectiva aparece 


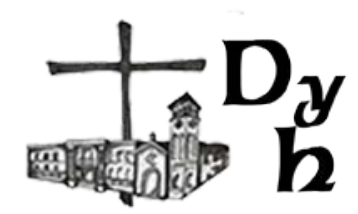

asociada a la plenitud de este acto, no como algo distinto, sino como acto del acto, como el resplandor de la luz(Cfr.Anchepe, 2013).

En segundo lugar y en continuación, vale decir que, si la locución intelectiva es considerada plenitud del acto de entendimiento, se considera igualmente que ella es aquello que entiende nuestro entendimiento $y$, por tanto, una representación de las cosas y un signo de las mismas. Se debe aclarar que al decir representación de las cosas no estamos haciendo alusión a una imagen de la cosa, o a una pintura de la misma, ni siquiera a una duplicación de la realidad en nuestramente, sino que afirmamos que el concepto o verbo es semejanza de las cosas entendidas -en otras palabras, son uno en la cualidad como hemos asentado anteriormente-, semejanza que guardan en la forma, no en su aspecto exterior.

Dice Santo Tomás: «Lo entendido en el inteligente es el concepto o verbo» (Tomás de Aquino, Summa contra Gentiles, IV, 11), y en otro pasaje «Tal concepción, o verbo mental (...) nace de algo y representa algo otro. Pues nace del entendimiento por su acto; pero es semejanza de la cosa entendida» (Tomás de Aquino, De Potentia, q. 8, a. 1, in c.).

De este modo, el conocimiento intelectual es apertura a la realidad de las cosas, manifiesta la realidad y no se encierra sobre sí mismo. La actividad intelectual implica entender lo que las cosas son y fijar ese entendimiento por medio de una locución, una palabra interna, que actúa como signo de la realidad.

Por último, debemos mostrar el vínculo que existe entre la locución intelectual y la autoconciencia. Párrafos anteriores mostramos que el alma humana es subsistente en sí misma por ser una substancia inmaterial, más allá de tener que informar al cuerpo. Esta es la condición que le permite ser inteligible para sí misma.

Sin embargo, no debemos caer en el exceso de creer que el conocimiento de sí llegue a ser una intelección, de evidencia objetiva, de la esencia el alma, sino mas bien, que se presenta como una percepción intelectual de su existencia. Es decir que, debido a su corporeidad y su condición de espíritu encarnado, el intelecto humano sólo posee un conocimiento habitualde sí, una disposición permanente que se actualiza en el acto de entender.

Hemos expuesto también, que en dicho acto se produce la asimilación de las esencias de las cosas, por lo cual, el papel de la conciencia de sí, se vuelve 
necesario debido a que esta presencia intelectiva asegura la intelectualidad propia del entendimiento humano y su consiguiente virtud receptiva de los inteligibles. Vale explicar nuevamente, que al ser el entendimiento humano el más bajo de los entendimientos (es decir, que su participación en el ser es la menor en el grado de vida intelectual), esta autopresencia del alma es mínima.

Al respecto declara el Aquinate: «Por eso, las sustancias inmateriales son inteligibles por su propia esencia en la medida en que les compete esencialmente existir en acto». $Y$ también «El entendimiento humano, con respecto a los seres inteligibles, está en pura potencia, como la materia prima en relación a lo sensible».

Por eso es llamada posible. Así, pues, considerado en su esencia, es sólo capacidad de entender. Por eso tiene, en cuanto tal, el poder de entender, pero no el de ser entendido hasta que no esté en acto». De este modo: "Nuestro entendimiento se conoce a sí mismo no por su esencia, sino por su acto»(Tomás de Aquino, Suma Teológica, q. 87, a. 1.).

\section{Errores opuestos}

Podríamos señalar varios errores opuestos al principio que orienta este trabajo dado que cualquier sistema de pensamiento que reduzca o modifique el alcance real del entendimiento humano, recorte su perspectiva metafísica, o parta de una idea de Hombre distinta a la cosmovisión realista, encontrará inviables ciertos pilares gnoseológicos expuestos en los apartados anteriores. Por tanto, elegiremos uno dentro de la amplitud que se nos propone.

Tomaremos, pues, de la gran obra del pensador alemán ArnoldGehlenEl hombre: su Naturaleza y su lugar en el mundo, ciertas tesis antropológicas que reducen la concepción del ser humano al plano biológico, en detrimento de su aspecto espiritual, lo cual repercute en el modo de conocer del mismo. El estudio antropológico que desarrolla en su libro es una fuerte tesis que, al día de hoy, varios pensadores contemporáneos sostienen y propician; de esto último, se desprende la justificación de la elección de dicho error.

Si bien el pensador alemán inicia su trabajo mostrando la apertura del hombre al mundo y la diferencia que éste tiene con los animales, los cuales sólo se 


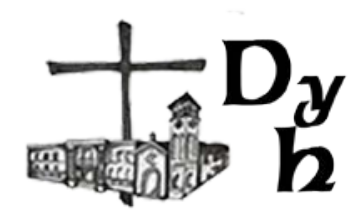

adaptan a un medio circundante, un mundo recortado, luego lo señala como principal límite de su existencia, como aspecto negativo de su ser humano.

Que el hombre está abierto al mundo quiere decir que carece de la adaptación animal a un ambiente-fragmento» (Gehlen, 1987, pág. 39). «Por el contrario nosotros tenemos en este momento el "bosquejo" de un ser carencial desde el punto de vista orgánico, por eso mismo abierto al mundo, es decir, incapaz por naturaleza de vivir en un ambiente fragmentario concreto(Gehlen, 1987, pág. 40).

De esta manera, la apertura al mundo del ser humano se transforma, o mejor dicho, es tomada como falencia del mismo ya que se convierte principalmente en una carga. Este error, brota de la reducción biológica que realiza del ser humano el autor, puesto que interpreta la apertura al mundo como insuficiencia orgánica que lo incapacita para vivir naturalmente en cualquier medio; la apertura al mundo queda registrada como exposición al mundo. Notamos entonces, que la distinción con los animales no se realiza en razón de la espiritualidad propia del hombre y su consecuente captación de la inteligibilidad de las cosas -lo que señalábamos como apertura a lo real en apartados anteriores-, sino que, la dotación insuficiente del hombre resalta como carácter distintivo.

Esta insuficiencia orgánica repercute en el ámbito gnoseológico del ser humano, y lleva por correlato la miseria del pensamiento, puesto que, de ahora en más, sólo será tomado este como creador de posibilidades para prolongar la existencia, sólo es un instrumento para «sacar de nosotros mismos» la perpetuación de nuestra vida.

Como la ley estructural del comportamiento humano sensomotor se continua en el lenguaje y como finalmente se hace comprensible lo peculiar de la inteligencia humana. Con otras palabras: de la complexión morfológica del hombre se siguen las tareas de transformación de los gravámenes elementales en medios para la conservación de la existencia y la prolongación de la vida(Gehlen, 1987, pág. 53).

En esta línea de pensamiento, tanto la vida social como cultural se ven afectadas y transformadas, convirtiéndose en elementos construidos por el 
pensamiento del hombre y modificados por el lenguaje para su propia supervivencia. «El conjunto de la naturaleza, transformada para que sirva a la vida del hombre» (Gehlen, Der Mensch, pág. 26 citado en Pieper, 2009, pág. 153).

A partir de lo expuesto, vemos que la reducción biológica del hombre, y en consecuencia del entendimiento humano, matiza el alcance del conocimiento humano. En otras palabras, al hacer depender la apertura hacia la realidad de las cosas de una insuficiencia orgánica, se pierde el eje de lo que se está tratando, no se percibe que esta característica del ser humano se encuentra fundada en su lado espiritual. A su vez, ésta virtud inmaterial, posibilita la recepción de las perfecciones de las cosas, que nos terminan enriqueciendo en última instancia, ya que, como hemos insistido una y otra vez, en el acto de conocimiento nos hacemos uno con las cosas.

Por consiguiente, el fin y la plenitud del hombre, también de su corporeidad, debemos buscarlo en lo más alto y perfecto que posee, en aquella dimensión inteligible -y por tanto espiritual y eterna-, que manifiesta además, lo más propio e íntimo de sí.

\section{Referencias}

Anchepe, I. M. (29 de 8 de 2013). Academia. Recuperado el 2018, de Inmanencia y conocimiento en Tomás de Aquino: a propósito del verbo mental: https://www.academia.edu/15764102/Inmanencia_y_conocimiento_en_Tom \%C3\%A1s_de_Aquino_a_prop\%C3\%B3sito_del_verbo_mental

Aristóteles. (s.f.). Acerca del Alma. Madrid: Gredos.

Aristóteles. (s.f.). Metafísica. Porrúa.

Bacigalupe, D. J. (2015). Las Representaciones Mentales en Santo Tomás de Aquino. Roma: EDUSC.

Blanco, G. P. (2002). Curso de Antropología Filosófica. Buenos Aires: EDUCA. Canals Vidal, F. (1987). Sobre la esencia del conocimiento. Barcelona: PPU. de Vío, T. (s.f.). In de Anima. 


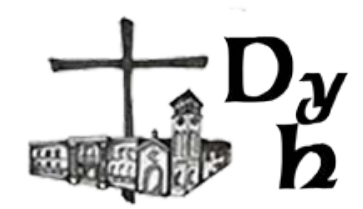

Derisi, O. N. (1945). La Doctrina de la Inteligencia. De Aristóteles a Santo Tomás. Buenos Aires: Cursos de Cultura Católica.

Forment, E. (2005). Id a Tomás. Principios fundamentales del pensamiento de Santo Tomás. Pamplona: Fundación Gratis Date.

Gehlen, A. (1987). El Hombre. Su naturaleza y su lugar en el mundo. Salamanca: Sígueme.

Hugón, E. O. (1946). Las Veinticuatro Tesis Tomistas. Buenos Aires: Poblet.

Pieper, J. (2009). La verdad de las cosas. (J. F. Franck, Trad.) Buenos Aires: Librería Córdoba.

Ponferrada, G. E. (2010). Carpeta de Gnoseología.Apuntes no editados. La Plata: Seminario San José.

Tomás de Aquino, S. (s.f.). De Potentia.Corpus Thomisticum: http://www.corpusthomisticum.org/

Tomás de Aquino, S. (s.f.). Quaestiones Disputatae de Veritate.Corpus Thomisticum: http://www.corpusthomisticum.org/

Tomás de Aquino, S. (s.f.). Suma Teológica. Madrid: B. A. C.

Tomás de Aquino, S. (s.f.). Summa contra Gentiles. Corpus Thomisticum:

http://www.corpusthomisticum.org/

Verneaux, R. (1988). Filosofía del Hombre (10ed.). París: Herder. 